\title{
Knowledge and Awareness on the Importance of Tender Coconut Water-A Survey
}

\author{
Abinaya. S', R. Gayatri Devi and A. Jothi Priya ${ }^{3}$ \\ ${ }^{1}$ Graduate student Department of physiology Saveetha Dental College, Saveetha Institute of \\ Medical and Technical Sciences (SIMATS) Saveetha University, Chennai, India. \\ ${ }^{2}$ Associate Professor, Department of Biochemistry, Saveetha Dental College and Hospitals, \\ Saveetha Institute of Medical and Technical Sciences, Saveetha University, Chennai 77, India \\ ${ }^{3}$ Professor, Department of Biochemistry, Saveetha Dental College and Hospitals, Saveetha Institute \\ of Medical and Technical Sciences, Saveetha University Chennai 77, India
}

\begin{abstract}
Tender coconut water is the clear liquid within a young fresh coconut. The benefits of coconut water includes reduced body heat, stomach pain and acts as digestive, applying in hair to promote hair growth. The aim of this study is to assess the knowledge and awareness of people about the importance of tender coconut water. A self-administered questionnaire comprising 10 questions was circulated to 100 people through an online google form. Before the study begins, the study detail was explained to the participants. The sample size of this study was 100 . The data was collected and statistically analysed. In this study, 90\% of the population were aware that tender coconut water hasn't had any effect on mental health and 10\% of the population were unaware of it. Around 86\% of the population were aware that tender coconut water contains antioxidant properties and 14\% of the population were not aware that it contains antioxidant properties. The overall result was positive, most of them were aware of the importance of tender coconut water. This proves an outright positive result. Through this survey, the majority of people were aware of the importance of tender coconut water.
\end{abstract}

KEY WORDS: AWARENESS; BENEFITS, IMPORTANCE; POPULAR SPORTS DRINK ; TENDER COCONUT WATER..

\section{INTRODUCTION}

Tender coconut water is one of the popular sport drinks. Cold sterilization of tender coconut water was undertaken using hollow fiber ultrafiltration (Campos et al., 1996). The water from the tender coconut has a pleasant sweet taste and is a refreshing drink. The principal inorganic constituent of nut water is potash. Promoting use of

\section{ARTICLE INFORMATION}

*Corresponding Author: gayatri.physio88@gmail.com Received 29th July 2020 Accepted after revision 24th Sep 2020 Print ISSN: 0974-6455 Online ISSN: 2321-4007 CODEN: BBRCBA

Thomson Reuters ISI Web of Science Clarivate Analytics USA and Crossref Indexed Journal

\section{Clarivate
Analytics}

NAAS Journal Score 2020 (4.31) SJIF: 2020 (7.728)

A Society of Science and Nature Publication,

Bhopal India 2020. All rights reserved.

Online Contents Available at: http//www.bbrc.in/

Doi: http://dx.doi.org/10.21786/bbrc/13.8/185 tender nuts as a source of health drinks and nutrition food will open up new opportunities for improving profitability of coconut farming (Reddy, Das and Das, 2005). Coconut water (coconut liquid endosperm), with its many applications, is one of the world's most adaptable natural products. Coconut water is suppressed of many amino acids, nitrogenous compounds, inorganic elements, organic acids, sugars and their alcohols, vitamins, growth substances (Cytokines and auxins) and many other unknown components. Tender coconut water is rich in essential minerals, like, potassium, sodium and natural nutrients, like, polyphenol. Coconut water was evaluated as rehydration fluid in diarrhoea. This refreshing liquor is consumed worldwide as it is nutritious and good for health (Jayanti et al., 2010).

Coconut water is commonly used as a growth supplement in plant tissue culture. Previously our team conducted

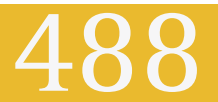


numerous studies and reviews on upcoming topics (Samuel and Devi, 2015; Baheerati and Gayatri Devi, 2018,Fathima and Preetha, 2016, Rj and R, 2016, Harsha et al., 2015 , Dave and Preetha, 2016,Shruthi and Preetha, 2018). The broad applications of coconut water can be sustained by its rare chemical composition of sugars, vitamins, minerals, amino acids and phytohormones (Maciel, Oliveira and Silva, 1992). Chemical composition and biological properties of coconut water were extensively studied (Laorko et al., 2017). The biologically pure, tender coconut water helps to compensate fluids, electrolytes (potassium, calcium, and magnesium), and sugars lost from the body during heavy physical exercise. It is used as a blood plasma supplant as it is sterile and readily established by the body (Gajanayaka, no date). Tender coconut water contains excessively efficient against both gram- positive and gram-negative bacteria. The fresh coconut water has a shelf life of about $24 \mathrm{~h}$ (Reddy et al., 2005) and that can be enhanced by ultrahigh temperature, pasteurization, refrigeration, freezing and microwave heating.

The tender coconut water has a strong tendency to undergo biochemical changes and spoilage, once the nuts are harvested from the tree. The use of coconut water resulted in longer sub-culturing time and the production of highly robust plants which were able to survive in greenhouse conditions. Tender coconut water has significant cardioprotective and antithrombotic effect in rats induced myocardial infarction. Tender coconut water showed potent hepatoprotective and antioxidant effects in carbon tetrachloride (CCl4)-intoxicated rats. Tender coconut water could inhibit and reverse high blood pressure, standardized antioxidant status and improve insulin sensitivity. Importance of tender coconut water reduces the body heat and stomach pain; acts as digestive; applying in hair to promote hair growth. Previously our team had conducted numerous studies and reviews on upcoming topics (Abigail et al., 2019; David et al., 2019 ,Choudhari and Jothipriya, 2016, Iyer, Gayatri Devi and Jothi Priya, 2019, Swathy and Gowri Sethu, 2015, R and Sethu, 2018 ,Timothy, Gayatri Devi and Jothi Priya, 2019) . The main aim of the study is to assess the awareness on the importance of tender coconut water among the population.

\section{MATERIAL AND METHODS}

A cross-sectional study was conducted with a selfadministered questionnaire with a sample size of 100 participants comprising the general population. The questionnaire consists of questions that help in socio economic data, questions that help in providing awareness among the participants and also consist of the questions related to facts. The questionnaire was validated in the standard manner. Measures such as selection of participants randomly, steps to prevent asking irrelevant, placing restrictions over the participants are followed to minimise the sampling bias. The questionnaire was circulated using the online platform Google Forms. Descriptive analysis was carried out using the statistical software SPSS VERSION 2.0. The results were analyzed and represented in a pie chart.

Figure 1: Pie chart representing the percentage distribution of awareness among study participants regarding that tender coconut water has any effect on mental health. Minority of participants (10\%) responded yes (blue), (90\%) responded no (red) .

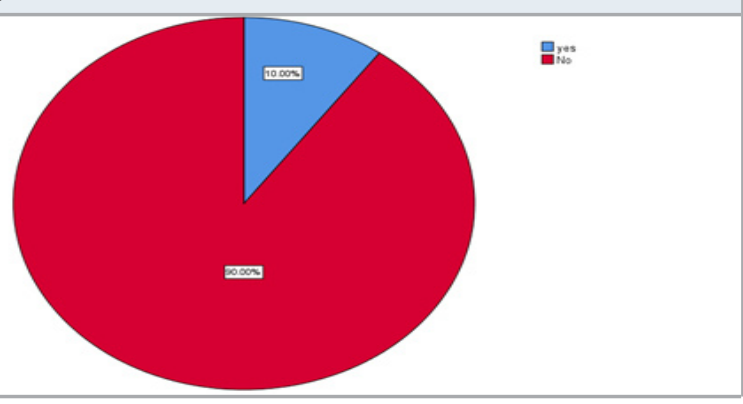

Figure 2: Pie chart representing the percentage distribution of awareness among study participants regarding that tender coconut water has any side effects. Majority of participants (85\%) responded no (red) and (15\%) responded yes (blue).

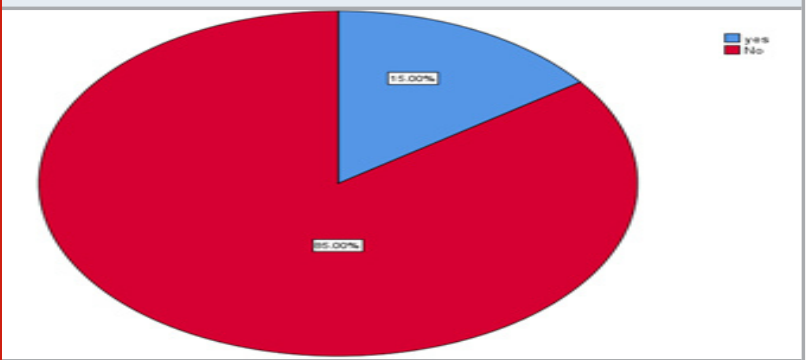

Figure 3: Pie chart representing the percentage distribution of awareness among study participants regarding whether over-drinking of tender coconut water leads to stomach upset. Majority of participants (80\%) responded yes (blue) and $(20 \%)$ responded no (red).

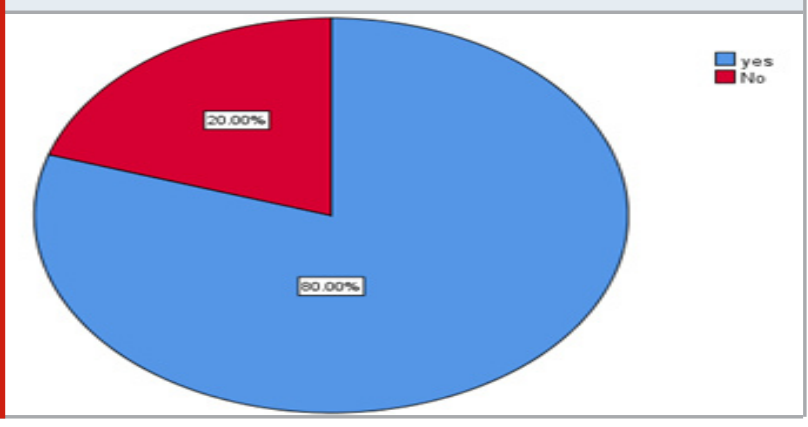

RESULTS AND DISCUSSIONS

In the present scenario, many of them were aware about the importance of tender coconut water. Majority 90\% of the survey population were aware that tender coconut water hasn't had any effect on mental health (figure 1). 
The similar findings were found in a previous study (Reddy et al., 2018). Around 85\% participants were known that tender coconut water hasn't had any side effects (figure 2), which was similar to findings of the previous study (Ramaswamy and F, 2017). Around $80 \%$ of people were aware that over-drinking of tender coconut water leads to stomach upset (figure 3) which was similar to the statement proved in the previous study $(\mathrm{V}$, Geetha and Bhavana, 2016). Around 65\% of people were aware that the tender coconut water keeps blood pressure at normal range (figure 4) which was homogenous to the existing studies. 98\% of the participants were aware that tender coconut water has an important role in blood pressure which was also stated by previous studies (Selvaraj et al., 2019).

Figure 4: Pie chart representing the percentage distribution of awareness among study participants regarding whether tender coconut water keeps blood pressure at normal range. Majority of participants (65\%) responded yes (blue), (35\%) responded no (red).

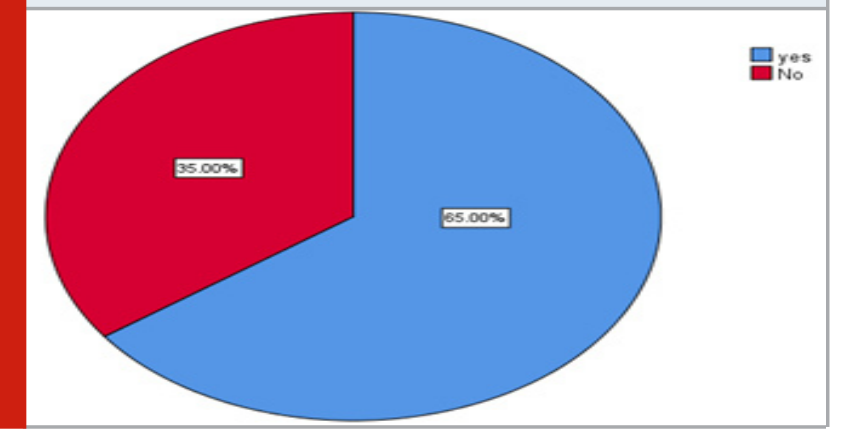

Figure 5: Pie chart representing the percentage distribution of awareness among study participants regarding whether tender coconut water reduced the stomach pain. Majority of participants (95\%) responded yes (blue), (5\%) responded no (red).
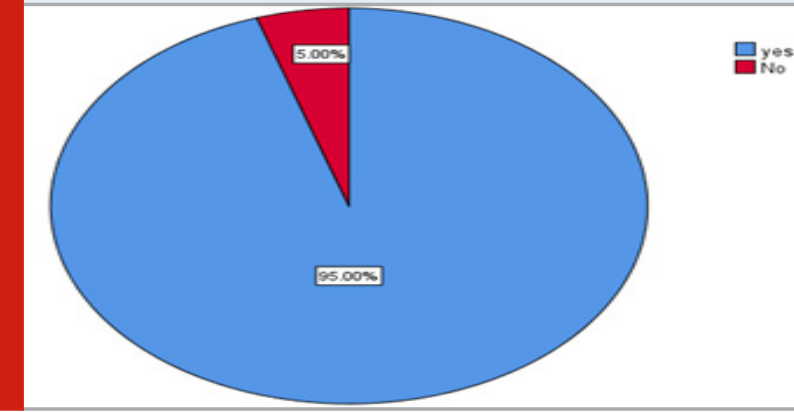

95\% of participants were aware that reduced stomach -pain within 10mins (figure 5). which was similar to findings of the previous studies (Delfiya, Aniesrani Delfiya and Thangavel, 2016). 98\% of participants were aware that tender coconut water reduced the body heat (figure 6). The similar finding was also found in a previous study(C et al., 2019). Around 70\% of the participants were aware that taking tender coconut water in an empty stomach helps in kick-starting the metabolism (figure 7) shown by the previous study (C et al., 2019; Chutia et al., 2019). 94\% of participants were aware that drinking tender coconut water helps in digestion (figure 8) which was proved by previous study (Chattopadhyay et al., 2013). Majority 86\% of participants were aware that tender coconut water has antioxidant properties (figure 9), which was similar to the statement proved in the previous study(Prathapan and Rajamohan, 2011).

Figure 6: Pie chart representing the percentage distribution of awareness among study participants regarding whether tender coconut water reduced the body heat. Majority of participants (98\%) responded yes (blue), (2\%) responded no (red).

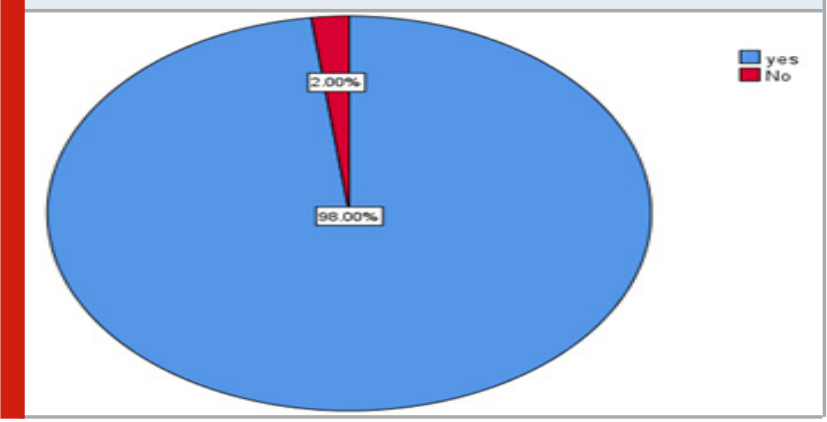

Figure 7: Pie chart representing the percentage distribution of awareness among study participants regarding whether taking tender coconut water in empty stomach helps in kick-starting the metabolism. Majority of participants (70\%) responded yes (blue), (30\%) responded no (red).

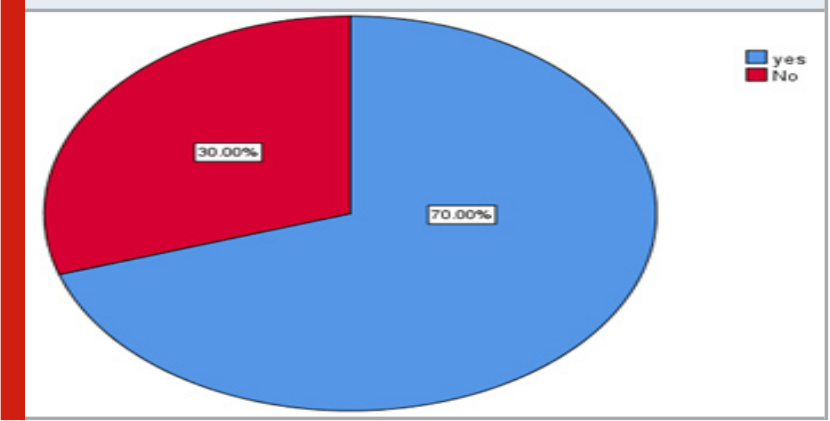

Figure 8: Pie chart representing the percentage distribution of awareness among study participants regarding whether drinking tender coconut water helps in digestion. Majority of participants (94\%) responded yes (blue), (6\%) responded no (red).

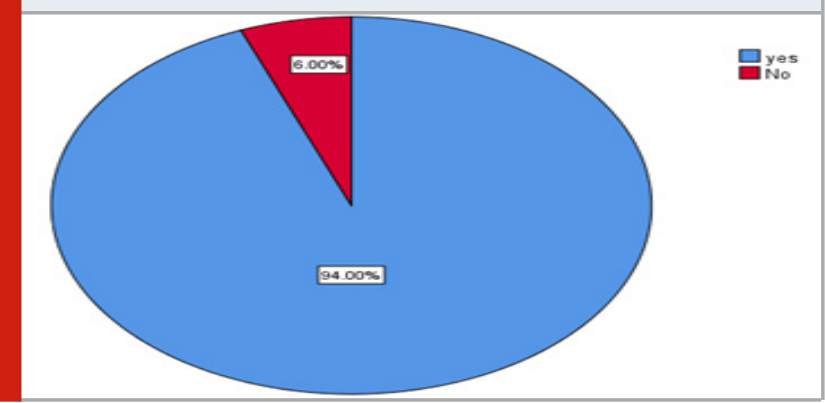


Figure 9: Pie chart representing the percentage distribution of awareness among study participants regarding whether tender coconut water has antioxidant properties. Majority of participants (86\%) responded yes (blue), (14\%) responded no (red).

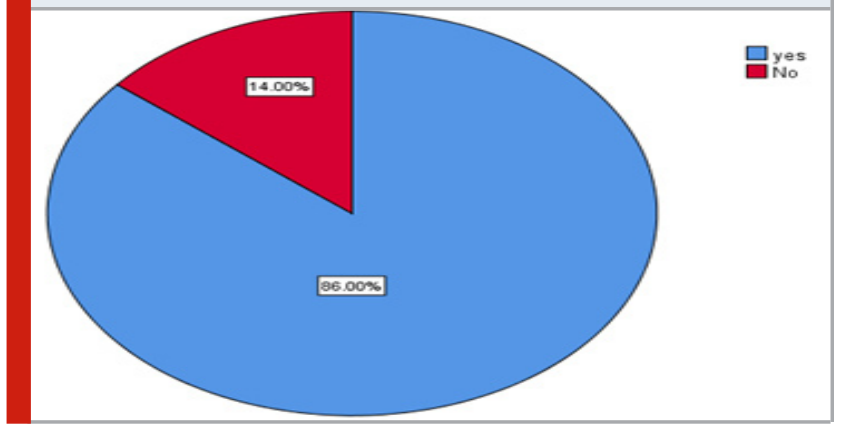

Figure 10: Pie chart representing the percentage distribution of awareness among study participants regarding whether tender coconut water helps to prevent kidney stones . Majority of participants (60\%) responded yes (blue), (40\%) responded no (red).

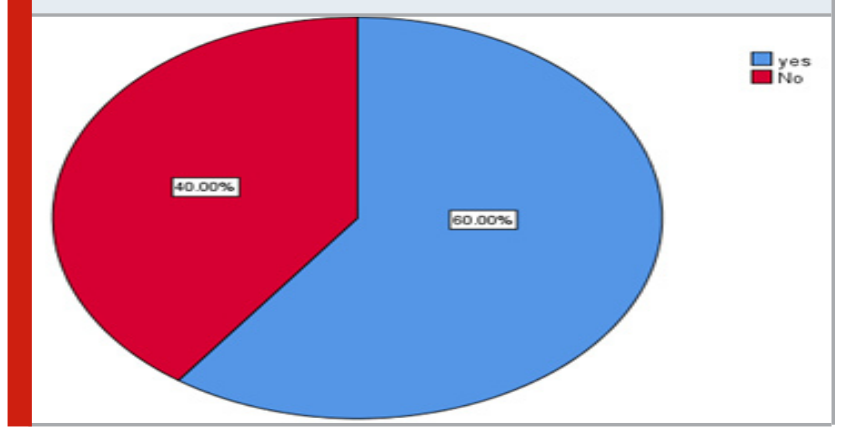

Figure 11: Bar chart represents association between gender and awareness of tender coconut water keeps blood pressure at normal range. $\mathrm{X}$-axis represents gender and $\mathrm{Y}$-axis represents the number of participants who were aware (blue) and not aware (red). Out of 65 participants who were aware, 36 participants constituted females and 29 participants constituted male. Females were more aware than males. Pearson's Chi-Square: 0.826 , p value: 0.042 $(<0.05)$ hence statistically significant.

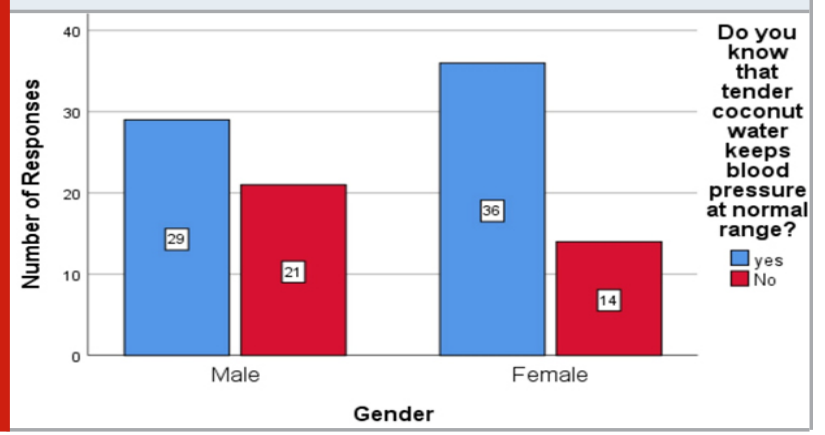

Around $60 \%$ of the participants were aware that tender coconut water helps to prevent kidney stones (figure 10), which was similar to the statement proved in the previous study (Zulaikhah and Wibowo, 2018). (figure 11). In this study, association between gender and awareness like tender coconut water keeps blood pressure at normal range was done using Chi-Square test. Out of $65 \%$ of the participants were aware, females were more aware than males (figure 12). Association between gender and awareness of the tender coconut water reduces the body heat as done using Chi-Square test. Out of $98 \%$ of the participants were aware, males were more aware about the tender coconut water reducing the body heat than males.The future scope to assess awareness about the importance of tender coconut water among the population.

Figure 12: Bar chart represents association between gender and awareness of tender coconut water reduces the body heat. $\mathrm{X}$-axis represents gender and $\mathrm{Y}$-axis represents the number of participants who were aware (blue) and not aware (red). Out of 98 participants who were aware, 50 participants constituted males and 48 participants constituted females. Males were more aware than females. Pearson's Chi-Square: 0.826, p value: 0.153 (>0.05) hence not statistically significant.

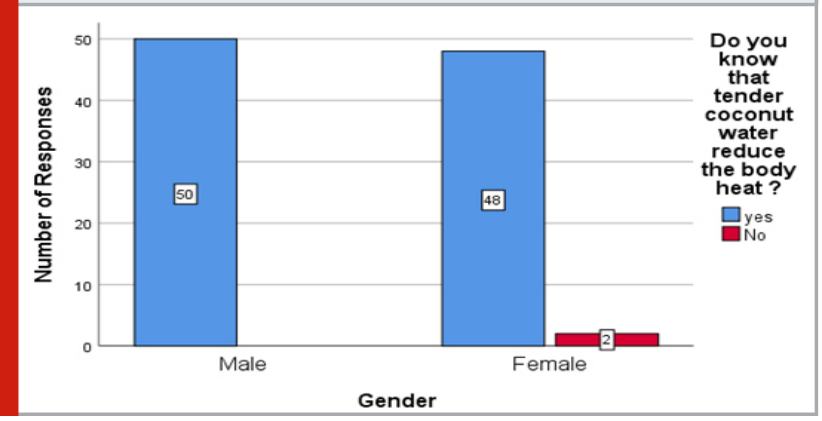

\section{CONCLUSION}

Based on this survey, it is evident that the majority of the participants were aware about tender coconut water importance. This study may help the people to gain knowledge on tender coconut and they tried to take regularly in order to maintain healthy life

\section{ACKNOWLEDGEMENTS}

We thank Saveetha Dental College for providing us the support to conduct the study.

Conflict of Interest: All the authors declare no conflict of interest in the study.

\section{REFERENCES}

Abigail et al. (2019) 'Evaluation of Muscular Endurance among Dentists', Indian Journal of Public Health Research \&t Development, p. 258. doi: 10.5958/09765506.2019.02808.0.

Baheerati, M. M. and Gayatri Devi, R. (2018) 'Obesity in relation to Infertility', Research Journal of Pharmacy and Technology, p. 3183. doi: 10.5958/0974360x.2018.00585.1. 
Campos, C. F. et al. (1996) 'CHEMICAL COMPOSITION, ENZYME ACTIVITY AND EFFECT OF ENZYME INACTIVATION ON FLAVOR QUALITY OF GREEN COCONUT WATER', Journal of Food Processing and Preservation, pp. 487-500. doi: 10.1111/j.17454549.1996.tb00761.x.

Chattopadhyay, N. et al. (2013) 'EVALUATION OF COCONUT CULTIVARS FOR TENDER NUT WATER', Acta Horticulturae, pp. 255-262. doi: 10.17660/ actahortic.2013.975.28.

Choudhari, S. and Jothipriya, M. A. (2016) 'Nonalcoholic fatty liver disease', Research Journal of Pharmacy and Technology, p. 1782. doi: 10.5958/0974360x.2016.00360.7.

Chutia, H. et al. (2019) 'Kinetics of inactivation of peroxidase and polyphenol oxidase in tender coconut water by dielectric barrier discharge plasma', LWT, pp. 625-629. doi: 10.1016/j.lwt.2018.11.071.

C, J. et al. (2019) 'SYBR Green Real-Time PCR Assay for Detection of the Indicator Bacillus cereus to Validate Thermal Processing of Tender Coconut Water', Journal of Pure and Applied Microbiology, pp. 1325-1334. doi: 10.22207/jpam.13.3.04.

Dave, P. H. and Preetha (2016) 'Pathogenesis and Novel Drug for Treatment of Asthma-A Review', Research Journal of Pharmacy and Technology, p. 1519. doi: 10.5958/0974-360x.2016.00297.3.

David et al. (2019) 'Physical Fitness among the Dental Physician, Dental Undergraduates and Postgraduates Students', Indian Journal of Public Health Research \&t Development, p. 223. doi: 10.5958/09765506.2019.02801.8.

Delfiya, D. S. A., Aniesrani Delfiya, D. S. and Thangavel, K. (2016) 'Effect of Ohmic Heating on Polyphenol Oxidase Activity, Electrical and Physicochemical Properties of Fresh Tender Coconut Water', International Journal of Food Engineering, pp. 691-700. doi: 10.1515/ ijfe-2015-0329.

Fathima, F. and Preetha, P. (2016) 'EVALUATION OF THYROID FUNCTION TEST IN OBESE PATIENTS', Asian Journal of Pharmaceutical and Clinical Research, p. 353. doi: 10.22159/ajpcr.2016.v9s3.12959.

Gajanayaka, I. S. (no date) 'DEVELOPMENT OF A VALUE ADDED BEVERAGE FROM MATURED COCONUT WATER'. doi: 10.31357/fapsmst.2006.00420.

Harsha, L. et al. (2015) 'Systemic Approach to Management of Neonatal Jaundice and Prevention of Kernicterus', Research Journal of Pharmacy and Technology, p. 1087. doi: 10.5958/0974-360x.2015.00189.4.

Iyer, P. K., Gayatri Devi, R. and Jothi Priya, A. (2019) 'A Survey Study on Causes, Treatment and Prevention of Onychocryptosis', Indian Journal of Public Health Research \& Development, p. 807. doi: 10.5958/0976-
5506.2019.01990.9.

Jayanti, V. K. et al. (2010) 'QUANTIFICATION OF FLUX DECLINE AND DESIGN OF ULTRAFILTRATION SYSTEM FOR CLARIFICATION OF TENDER COCONUT WATER', Journal of Food Process Engineering, pp. 128-143. doi: 10.1111/j.1745-4530.2008.00264.x.

Laorko, A. et al. (2017) 'Cold Sterilization of Coconut Water Using Membrane Filtration: Effect of Membrane Property and Operating Condition', Journal of Applied Membrane Science \&t Technology. doi: 10.11113/amst. v7i1.56.

Maciel, M. I., Oliveira, S. L. and Silva, I. P. (1992) 'EFFECTS of DIFFERENT STORAGE CONDITIONS ON PRESERVATION of COCONUT (Cocos nucifera) WATER', Journal of Food Processing and Preservation, pp. 13-22. doi: 10.1111/j.1745-4549.1992.tb00189.x.

Prathapan, A. and Rajamohan, T. (2011) 'ANTIOXIDANT AND ANTITHROMBOTIC ACTIVITY OF TENDER COCONUT WATER IN EXPERIMENTAL MYOCARDIAL INFARCTION', Journal of Food Biochemistry, pp. 1501-1507. doi: 10.1111/j.1745-4514.2010.00471.x.

Ramaswamy, L. and F, Z. F. (2017) 'Formulation and Acceptability of Sports Drinks using Fruit Juices and Tender Coconut Water', CORD, p. 7. doi: 10.37833/cord. v33i1.55.

Reddy, E. P. et al. (2018) 'Tender Coconut Water Uses, Health Benefits, Good Nutritive Value and Antioxidant Capacity', Indian Journal of Public Health Research \&t Development, p. 184. doi: 10.5958/09765506.2018.00280.2.

Reddy, K. V., Das, M. and Das, S. K. (2005) 'Filtration resistances in non-thermal sterilization of green coconut water', Journal of Food Engineering, pp. 381-385. doi: 10.1016/j.jfoodeng.2004.08.029.

R, G. D. and Sethu, G. (2018) 'EVALUATION OF ADENOIDS BY ORONASAL AND NASAL SPIROMETRY', Asian Journal of Pharmaceutical and Clinical Research, p. 272. doi: 10.22159/ajpcr.2018.v11i10.27365.

Rj, I. and R, G. D. (2016) 'Role of environmental factors on sleep patterns of different age groups', Asian Journal of Pharmaceutical and Clinical Research, p. 124. doi: 10.22159/ajpcr.2016.v9i6.13832.

Samuel, A. R. and Devi, M. G. (2015) 'Geographical distribution and occurrence of Endemic Goitre', Research Journal of Pharmacy and Technology, p. 973. doi: 10.5958/0974-360x.2015.00162.6.

Selvaraj, K. S. V. et al. (2019) 'Evaluation of indigenous and exotic tall and dwarf coconut genotypes for quality tender coconut water trade', Progressive Agriculture, $p$. 88. doi: 10.5958/0976-4615.2019.00011.5.

Shruthi, M. and Preetha, S. (2018) 'Effect of Simple Tongue Exercises in Habitual Snorers', Research Journal of Pharmacy and Technology, p. 3614. doi: 
10.5958/0974-360x.2018.00665.0.

Swathy, S. and Gowri Sethu, V. (2015) 'Acupuncture and lower back pain', Research Journal of Pharmacy and Technology, p. 991. doi: 10.5958/0974360x.2015.00165.1.

Timothy, C. N., Gayatri Devi, R. and Jothi Priya, A. (2019) 'Evaluation of Peak Expiratory Flow Rate (PEFR) in Pet Owners', Indian Journal of Public Health Research \&t Development, p. 803. doi: 10.5958/09765506.2019.01989.2.
V, G., Geetha, V. and Bhavana, K. P. (2016) 'Studies on the Composition and In-Vitro Antioxidant Activities of Concentrates from Coconut Testa and Tender Coconut Water', Journal of Food Processing \& Technology. doi: 10.4172/2157-7110.1000588.

Zulaikhah, S. T. and Wibowo, J. W. (2018) 'The Effect of Tender Coconut Water on Free Radical Due to Mercury Exposure', International Journal of Public Health Science (IJPHS), p. 102. doi: 10.11591/ijphs. v7i2.11849. 